\title{
Synthesis and characterization of cobalt oxide and composite thin films
}

\author{
Ulrika Lagerqvist, Mikael Ottosson, Annika Pohl* \\ Dept. of Chemistry-Ångström, Ångström Laboratory, Uppsala university, Uppsala, Sweden
}

Email address:

pohl@kemi.uu.se (A. Pohl)

\section{To cite this article:}

Ulrika Lagerqvist, Mikael Ottosson, Annika Pohl. Synthesis and Characterization of Cobalt Oxide and Composite Thin Films. Advances in Materials. Vol. 3, No. 5, 2014, pp. 52-57. doi: 10.11648/j.am.20140305.14

\begin{abstract}
Cobalt oxide and composite thin films were synthesized by spin-coating technique, followed by heating to $500^{\circ} \mathrm{C}$ in oxidizing, inert, or reducing atmospheres. Methanolic solutions of triethanolamine complexes of cobalt acetates and nitrates were spin-coated at 1000, 2000, and $3000 \mathrm{rpm}$. The influence of heating parameters and film thickness on the phase content of the films were investigated, using grazing incidence X-ray diffraction, X-ray reflectivity, and scanning electron microscopy. By tuning the synthesis parameters, $\mathrm{Co}_{3} \mathrm{O}_{4}, \mathrm{CoO}$ and $\mathrm{Co}$ films were obtained, as well as $\mathrm{CoO}-\mathrm{Co}$ and $\mathrm{Co}_{3} \mathrm{O}_{4}-\mathrm{CoO}$ composite films of varying phase ratios.
\end{abstract}

Keywords: Cobalt Oxides, Coo-Co Composites, Solution Synthesis, Thin Films, Tailor Composition

\section{Introduction}

Cobalt oxides have attracted much attention for their interesting fundamental properties and many technical applications. Co forms two stable oxides, $\mathrm{CoO}$ and $\mathrm{Co}_{3} \mathrm{O}_{4}$. $\mathrm{Co}_{3} \mathrm{O}_{4}$ is an antiferromagnetic compound with mixed valence $\left(\mathrm{CoIICoIII} \mathrm{O}_{4}\right)$. Due to the stability of the low-spin d6 ion in an octahedral crystal field, $\mathrm{Co}_{3} \mathrm{O}_{4}$ has a regular spinel structure with $\mathrm{Co}^{3+}$ in octahedral sites and $\mathrm{Co}^{2+}$ in tetrahedral sites. The most stable form of $\mathrm{CoO}$ has a rock-salt structure and is antiferromagnetic below $289 \mathrm{~K} \mathrm{[1]}$. The ability of cobalt to display several oxidation states constitutes the foundation for numerous applications in many different fields: Cobalt oxides and composites can be used for catalysis of $e . g$. NO decomposition [2,3], intercalation compounds for energy storage such as rechargeable (Li-ion) batteries [4-7], gas sensors [8,9], and in electrochromic devices [10-12]. They are also widely studied for their attractive magnetic properties [13-15].

Cobalt has a high affinity for oxygen and thus readily forms oxides. This is a reason why it can be difficult to synthesize pure nanophase cobalt metal, and it can also be a challenge to synthesize $\mathrm{CoO}$, since $\mathrm{CoO}$ easily oxidizes to $\mathrm{Co}_{3} \mathrm{O}_{4}$ when heated in the presence of oxygen $[1,15]$. $\mathrm{CoO}$ and $\mathrm{Co}_{3} \mathrm{O}_{4}$ have been prepared by a range of methods including sol-gel synthesis [12,16,17], co-precipitation, [17] spray pyrolysis [18], electrodeposition [19,20], chemical vapour deposition (CVD) [9], thermal decomposition [21], solvothermal synthesis [15], microemulsion [22,23], pulsed laser deposition (PLD) [24] and sputtering [11]. CoO can also be obtained by hydrogen reduction of $\mathrm{Co}_{3} \mathrm{O}_{4}$ or $\mathrm{CoO}(\mathrm{OH})$ $[25,26]$. Some of these methods can be used for preparation of thin films while others are more suitable for preparation of powders and nanoparticles.

Solution chemical synthesis methods are interesting as they provide versatile ways of synthesizing different materials: They can be used for preparation of films through e.g. spin-coating or dip-coating, as well as for preparation of powders and highly porous materials. Sol-gel and similar processes are also easy to modify or adapt in order to make complex oxides and composites, and they are attractive to use since there is a wide selection of precursors available. In sol-gel synthesis, alkoxides are generally the preferred precursors, and examples of Co-compounds synthesized via alkoxides in the literature, are for instance Co-doped $\mathrm{ZnO}$ and $\mathrm{TiO}_{2}$ [27-30], and $\mathrm{La}_{1-\mathrm{x}} \mathrm{Sr}_{\mathrm{x}} \mathrm{CoO}_{3}$ perovskites [30-32]. However, cobalt compounds synthesized from pure alkoxide routes are rare, the reason is the limited number of soluble monometallic cobalt alkoxides, and furthermore these alkoxides are difficult to prepare. As a result, for solution-based synthesis of cobalt compounds, rather than 
using alkoxides, the most commonly used precursors are metal salts, such as acetates and citrates. An advantage of these salts is that they are both inexpensive and easily dissolved in common solvents, such as water and alcohols, making the processes attractive for up-scaling. The drawback is that, when leaving the alkoxide routes, much of the control of morphology and phase composition is lost. It is therefore of great interest to further develop and study salt-based synthesis in order to regain the fine tuning possibilities.

Herein, we describe the preparation of single-phase and composite thin films of cobalt oxides $\mathrm{CoO}$ and $\mathrm{Co}_{3} \mathrm{O}_{4}$, and cobalt metal $(\mathrm{Co})$, using a solution route where cobalt salts and organic complexing agents are reacted through balanced red-ox reactions during heat-treatment under inert $\left(\mathrm{N}_{2}\right.$ or $\left.\mathrm{Ar}\right)$, oxidizing $\left(\mathrm{O}_{2}\right)$, or reducing $\left(\mathrm{Ar} / \mathrm{H}_{2}\right)$ atmosphere. The precursor system was reported by Westin et al. for preparation of nanophase metal through heating in nitrogen or argon atmosphere $[33,34]$, however we find that this results in small amounts of $\mathrm{CoO}$ and that addition of $\mathrm{H}_{2}$ is essential to obtain pure metal. The possibility to prepare films consisting of small metal nanoparticles makes this process highly interesting also for synthesis of nanophased oxides and metal-oxide composites. The method is also easily applied for doping with other transition metals, for powder synthesis as well as coatings on various materials, and for industrial up-scaling thereof.

\section{Experimental Procedure}

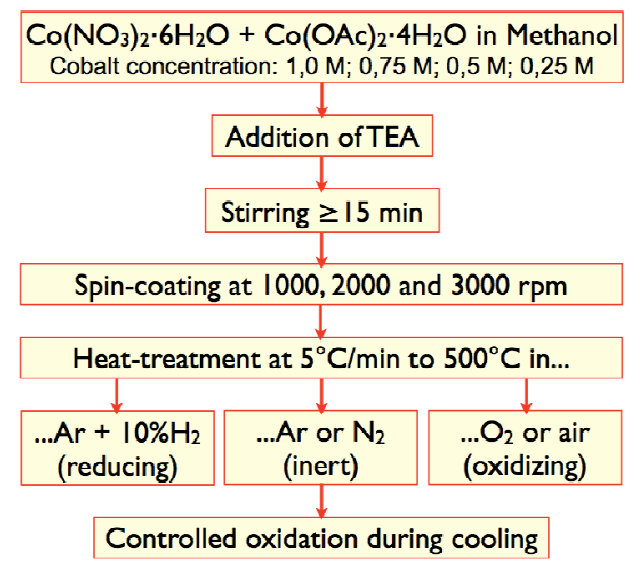

Figure 1. Preparation of cobalt oxides and composites films.

The synthesis is outlined in Figure 1. Four methanolic cobalt solutions with concentrations $0.25,0.50,0.75$ and 1.0 $\mathrm{M}$ were prepared from the hydrated nitrate and acetate salts $\mathrm{Co}\left(\mathrm{NO}_{3}\right)_{2} \cdot 6 \mathrm{H}_{2} \mathrm{O}$ and $\mathrm{Co}(\mathrm{OAc})_{2} \cdot 4 \mathrm{H}_{2} \mathrm{O}$. The four different concentrations were used to investigate the influence of concentration on film thickness in order to be able to tailor thickness. After dissolution in methanol $(\mathrm{MeOH})$, the complexing agent triethanolamine (TEA) was added under stirring. The salts were added in the molar ratio 9:1 $\mathrm{NO}_{3}: \mathrm{OAc}$, and TEA was added in the molar ratio 0.5:1 TEA:Co. To investigate the influence of spin velocity on film thickness, films were prepared by spin-coating silicon substrates at 1000 ,
2000 and $3000 \mathrm{rpm}$, for 50 seconds, followed by heat-treatment to $500^{\circ} \mathrm{C}$ at $5^{\circ} \mathrm{C} / \mathrm{min}$. To tailor the phase content inert, oxidizing and reducing atmospheres were used: Flowing nitrogen $\left(\mathrm{N}_{2}\right)$ or argon $(\mathrm{Ar})$, air or oxygen $\left(\mathrm{O}_{2}\right)$, and argon with $10 \%$ hydrogen $\left(\mathrm{Ar} / \mathrm{H}_{2}\right)$, respectively. A weakly oxidizing nitrogen atmosphere with $1 \%$ oxygen was used for some samples.

Studies of the effect on phase ratios of changing atmospheres from inert to oxidizing during cooling was performed on films prepared by spin-coating $1.0 \mathrm{M}$ or $0.75 \mathrm{M}$ solution at $3000 \mathrm{rpm}$.

In order to study the decomposition process during heat-treatment, thermo-gravimetric analysis (TGA) was performed on $5 \times 5 \mathrm{~mm}$ films in inert (Ar) and oxidizing $\left(\mathrm{O}_{2}\right)$ atmosphere, using a PerkinElmer Pyris 1 TGA Thermogravimetric Analyzer. TGA was also performed on powder samples prepared from small amounts of cobalt solutions, from which most of the solvent had been evaporated immediately prior to the start of the TGA analysis. TGA was carried out at $5^{\circ} \mathrm{C} / \mathrm{min}$ for powder as well as for film samples.

The morphology and thickness of the films were analyzed in a scanning electron microscope LEO 1550 (SEM). The identification of the crystalline phases in the films was made with grazing incidence X-ray diffraction (GIXRD) on a Philips X'Pert MRD diffractometer with a parallel beam set-up using $\mathrm{CuK} \alpha$ radiation, a primary $\mathrm{Ni} / \mathrm{C} \mathrm{X}$-ray mirror and a secondary $0.18^{\circ}$ parallel plate collimator and flat graphite monochromator. The incidence angle was typically $2^{\circ}$, but in order to vary the information depth an incidence angle of $0.35^{\circ}$ was used in addition to $2^{\circ}$. In order to avoid oxidation by air exposure, some samples heated in inert and reducing atmosphere were taken directly from the furnace into a glove-box in a sealed furnace tube, and GIXRD was measured using a sample holder equipped with a dome for protective atmosphere. The diffractometer used in these inert experiments was Siemens D5000 with a parallel beam set-up: $\mathrm{Ni} / \mathrm{C}$ primer X-ray mirror and $0.40^{\circ}$ parallel plate soller detector.

Film thickness was measured by X-ray fluorescence (XRF), on a PANalytical Epsilon 5 with a tungsten anode and a germanium secondary target, using the integrated area of the Co K $\alpha$-peak (6.824-7.023 keV, $180 \mathrm{~s})$, and standards obtained by X-ray reflectivity (XRR). XRR was measured in the Philips MRD diffractometer using an X-ray mirror and a $0.09^{\circ}$ parallel plate collimator. The thickness was determined from the oscillation frequency using the program Reflectivity from PANalytical.

\section{Result and Discussion}

Thermo-gravimetric analysis (TGA) of spin-coated films showed a continuous weight-loss, starting at $70-80^{\circ} \mathrm{C}$ and finishing around $320^{\circ} \mathrm{C}$ or $440^{\circ} \mathrm{C}$ for heating in oxygen or argon, respectively (figure 2). This is in agreement with the observations made for synthesis of metal powders by heat-treatment in nitrogen, where a dependence of the 
reaction pathway on the amount of materials was observed [33]. Westin et al. observed that large amounts of materials results in a two-step combustion process, whereas a continuous process is obtained for small amounts of material [33]. The TGA of films is consistent with the observations made for powders, as the films follow the slow continuous reaction pathway due to the small amount of reacting material in the gel film.

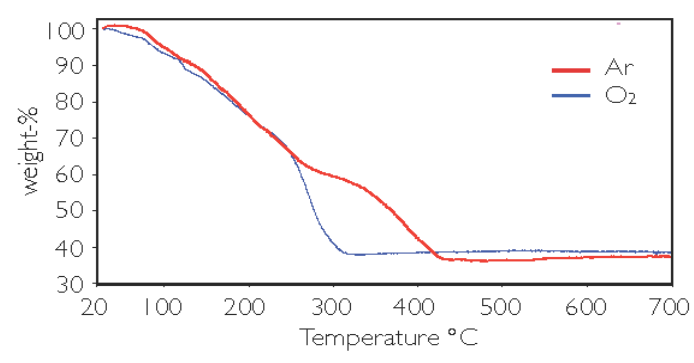

Figure 2. Thermo-gravimetric analysis of films in $\mathrm{Ar}$ and $\mathrm{O}_{2}$ atmospheres.

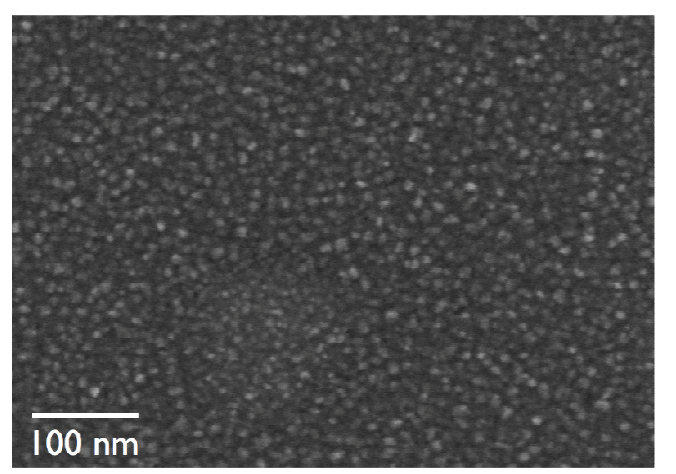

Figure 3. SEM micrograph of the film surface for a film prepared by spin-coating a $1.0 \mathrm{M}$ solution at $3000 \mathrm{rpm}$ followed by heating to $500^{\circ} \mathrm{C}$ in $\mathrm{Ar}$ atmosphere.

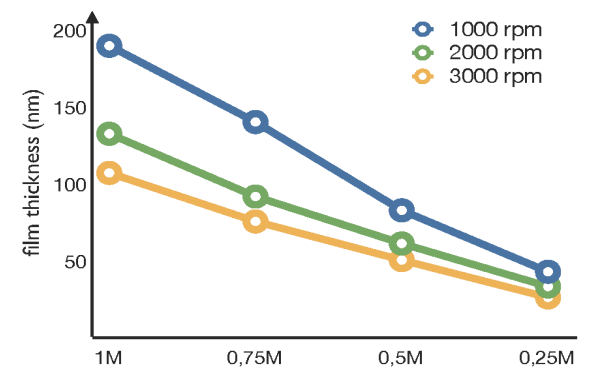

Figure 4. Film thickness as measured by XRF of films spin-coated for $50 \mathrm{~s}$ at: $1000 \mathrm{rpm}, 2000 \mathrm{rpm}$, and $3000 \mathrm{rpm}$, as a function of solution concentration.
SEM analyses showed excellent adhesion and that the films were composed of $c a 10 \mathrm{~nm}$ particles (figure 3). Film thickness for all films was measured by XRF, and in some cases also on cross section samples in the SEM. As shown in figures 4 and 5 , the film thickness depends on the concentration of the precursor solution, and on spin velocity: it decreases with increasing spin velocity, and with decreasing concentration. The spinning rate has larger effect for solutions of higher concentrations, but the dependence on concentration for a given spin velocity is roughly linear, allowing for tailoring of film thickness. By heating the spin-coated films to $500^{\circ} \mathrm{C}$ in inert atmosphere, followed by oxidation at room temperature, $\mathrm{Co}-\mathrm{CoO}$ composite films were obtained. For the thick films obtained from 1.0 and $0.75 \mathrm{M}$ solutions, the films consisted of two relatively well-defined layers, as observed by XRR measurements (figure 6). The increased intensity at $0.75-0.90^{\circ}$ is due to total reflection from the layers interface. The overlapping thickness fringes indicate a relatively smooth film of uniform overall film thickness. Cross section SEM (figure 6) shows that the top-layer of particles form a more dense structure compared to the particles in the rest of the film. The sintered top-layer could be due to an increased temperature resulting from a more exothermic fast reaction pattern due to more materials in thicker films. GIXRD analyses comparing the entire film and the surface of the film (i.e. at incidence angle $2^{\circ}$ and $0.35^{\circ}$ respectively), showed that there is an increased metal content in the surface layer of the film, while the "bulk" consists of relatively more $\mathrm{CoO}$ (figure 7). Holes in the compact layer allows for oxygen to penetrate and oxidise the bulk particles during the post-oxidation, but together with the thickness of the film it may also contribute to trap impurities in the film. The increased background around $45-55^{\circ}$ in the $2^{\circ} \mathrm{XRD}$ pattern, likely stems from amorphous carbon impurities and/or small amounts of hexagonal $\mathrm{Co}$ metal. The increased amount of $\mathrm{Co}$ in the sintered surface layer is consistent with studies of films with larger particles, prepared from the same precursor system, where a single layer of sintered particles were found to compose a metal core with a thin oxide layer covering the core on all sides, i.e. top, bottom and the sides of holes in the sintered layer [35].

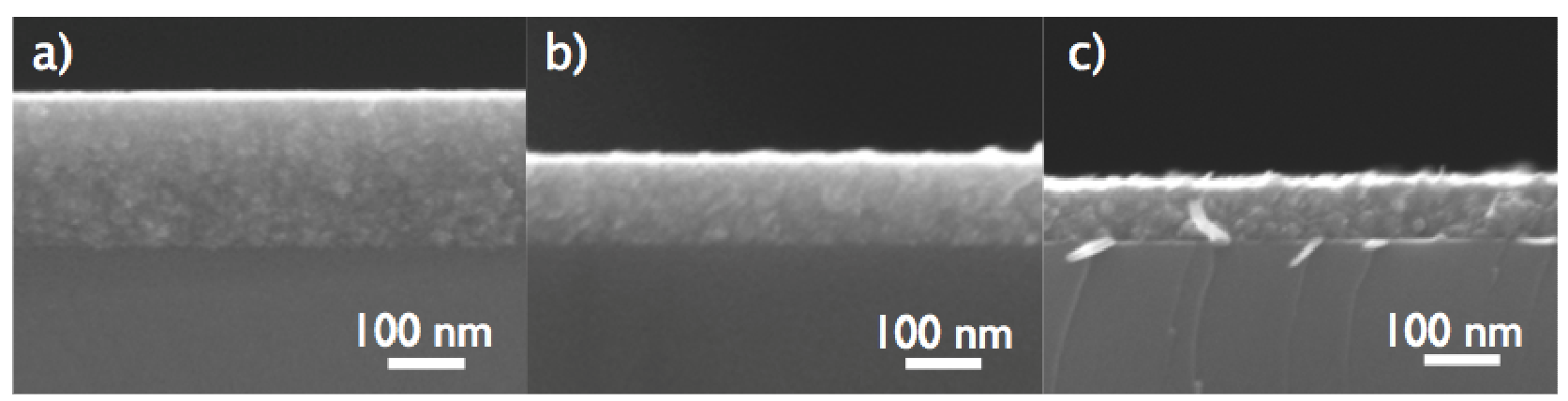

Figure 5. SEM micrograph of cross sections of films prepared by spin-coating a $1.0 \mathrm{M}$ solution at (a) $1000 \mathrm{rpm}$, (b) $2000 \mathrm{rpm}$ and (c) $3000 \mathrm{rpm}$. 

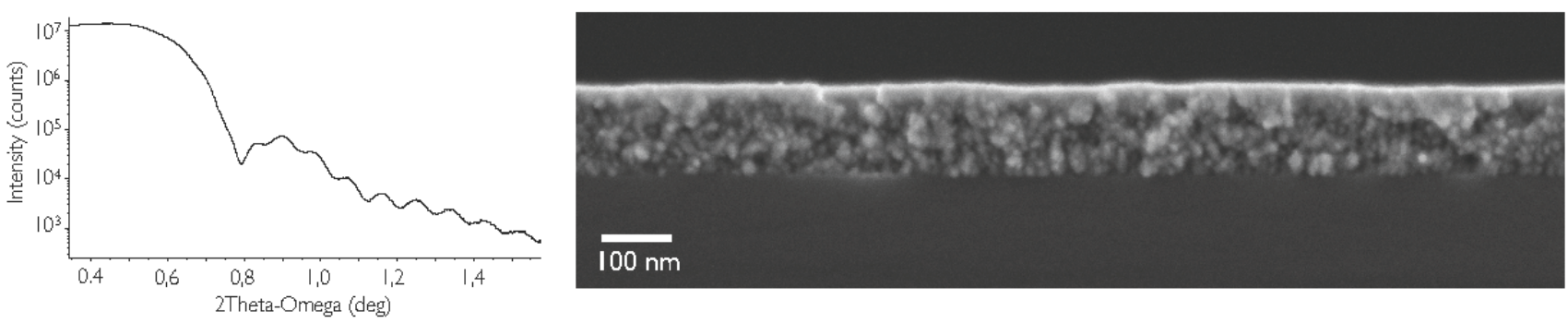

Figure 6. XRR pattern (left) for a film prepared by spin-coating a $0.75 \mathrm{M}$ solution at $2000 \mathrm{rpm}$, indicating a bilayer structure and a uniform overall film thickness, and corresponding SEM cross section micrograph (right) showing a denser top layer and a uniform overall film thickness.

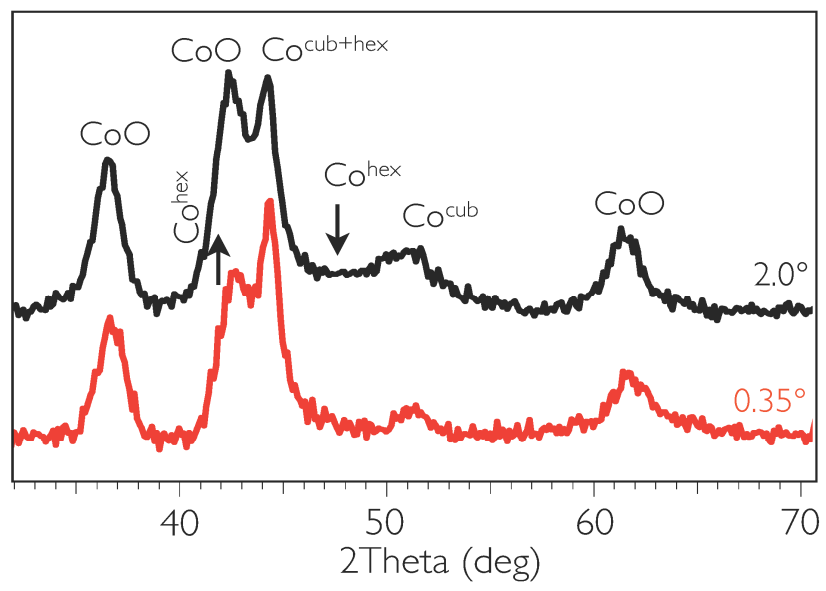

Figure 7. GIXRD at incidence angles of $2^{\circ}$ and $0.35^{\circ}$. The diffraction patterns recorded at $0.35^{\circ}$ has a larger relative contribution from the surface, compared to the pattern recorded at $2^{\circ}$, which has a larger relative contribution from the film bulk.

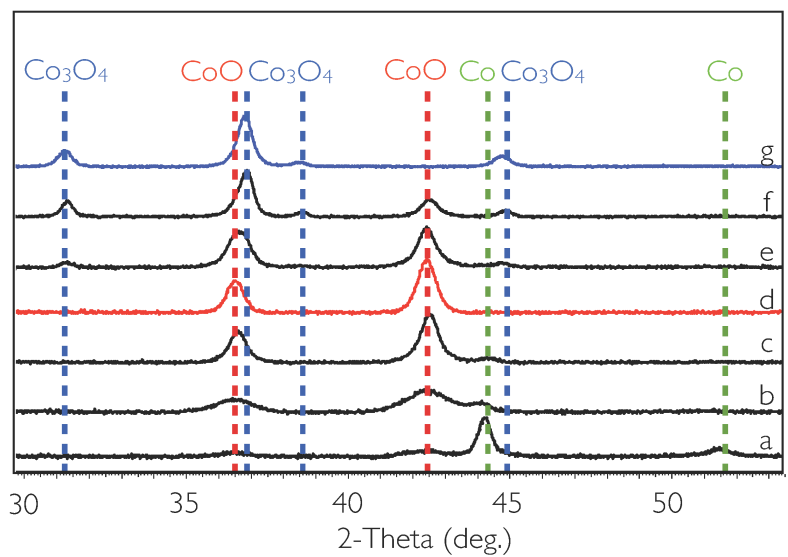

Figure 8. GIXRD of films prepared from spin-coating a $1.0 \mathrm{M}$ solution at $3000 \mathrm{rpm}$. CoO was obtained by heating in nitrogen followed by cooling in oxygen from $120^{\circ} \mathrm{C}$, changing to oxygen at lower temperatures resulted in CoO-Co composite films, e.g $100^{\circ} \mathrm{C}$ (b) and room temperature (a). Phase pure $\mathrm{Co}_{3} \mathrm{O}_{4}(\mathrm{~g})$ was obtained by heating in nitrogen with $1 \% \mathrm{O}_{2}$, whereas heating in pure nitrogen followed by addition of $1 \% \mathrm{O}_{2}$ on cooling resulted in composite films or $\mathrm{CoO}$, depending on the temperature of the oxygen addition: $500^{\circ} \mathrm{C}(f) 490^{\circ} \mathrm{C}(\mathrm{e}), 450^{\circ} \mathrm{C}(\mathrm{d}), 400^{\circ} \mathrm{C}(\mathrm{c})$.

As seen in figure 8, the phase content of the films was varied by altering the heat-treatment atmospheres. Thus, heating in oxidizing atmosphere, i.e. oxygen or air, resulted in single phase $\mathrm{Co}_{3} \mathrm{O}_{4}$ films, whereas single phase $\mathrm{CoO}$ films were obtained by switching gases from inert to air or $\mathrm{O}_{2}$ at $120^{\circ} \mathrm{C}$ on cooling down. Heating in inert atmosphere $\left(\mathrm{N}_{2}\right.$ or Ar) yielded Co-CoO mixed phases. This is different from the results reported by Westin et al., who obtained phase pure fcc Co metal on heating in $\mathrm{N}_{2}$ to $500^{\circ} \mathrm{C}$. However, we found small amounts of $\mathrm{CoO}$ present even when the sample remained unexposed to air, handled and analyzed under inert atmosphere, and that to obtain completely unoxidized films heating in reducing $\left(\mathrm{Ar} / \mathrm{H}_{2}\right)$ atmosphere was necessary, resulting in fcc cobalt metal with small amounts of the hep cobalt phase (figure 9).

The relative ratio of the two phases depended on the thickness of the film, as for thicker films a larger fraction remained unoxidized. Thus the $\mathrm{Co}: \mathrm{CoO}$ ratios could be varied through the concentration of the solution and the spin velocity, the later having the largest impact on thickness and thus on phase composition; The films made from the $1.0 \mathrm{M}$ solution contained large amounts of cubic $\mathrm{Co}$, as well as small amounts of hexagonal $\mathrm{Co}$, and cubic $\mathrm{CoO}$, whereas films made from the $0.25 \mathrm{M}$ solutions contained $\mathrm{CoO}$ and only very small (if any) Co metal (figure 10). For $1.0 \mathrm{M}$ and $0.75 \mathrm{M}$, $\mathrm{CoO}$ was obtained by changing from inert to oxidizing atmosphere at $120^{\circ} \mathrm{C}$, while inert cooling all the way to room temperature resulted in a partly oxidized film. By changing atmospheres at temperatures between $120^{\circ} \mathrm{C}$ and room temperature, films of intermediate $\mathrm{Co}-\mathrm{CoO}$ ratios could be obtained (figure $8 \mathrm{a}-\mathrm{b}$ ).

In inert atmosphere almost all $\mathrm{Co}$ (II) is reduced to metal by the organic components during the decomposition stage of the heat-treatment. This part of the heating is also when the films are most sensitive to oxidation. Heating in $\mathrm{N}_{2}$ with $1 \% \mathrm{O}_{2}$ resulted in $\mathrm{Co}_{3} \mathrm{O}_{4}$, while heating in $\mathrm{N}_{2}$ to $450^{\circ} \mathrm{C}$, at which point the decomposition is completed, and then change to the $1 \% \mathrm{O}_{2}$ mixture resulted in $\mathrm{CoO}-\mathrm{Co}_{3} \mathrm{O}_{4} . \mathrm{CoO}-\mathrm{Co}_{3} \mathrm{O}_{4}$ composite films were also obtained by changing atmospheres during cooling from inert to $1 \% \mathrm{O}_{2}$ in $\mathrm{N}_{2}$ from $500-480^{\circ} \mathrm{C}$ to room temperature, while changing at lower temperatures $\left(\leq 450^{\circ} \mathrm{C}\right)$ resulted in $\mathrm{CoO}$ or $\mathrm{CoO}-\mathrm{Co}$. Thus the combination of temperature and atmosphere can be used to modify the phase composition of the films (figure $8 \mathrm{c}-\mathrm{g}$ ). However, unlike the $\mathrm{CoO}-\mathrm{Co}$ composites, the $\mathrm{CoO}-\mathrm{Co}_{3} \mathrm{O}_{4}$ composites showed no tendency of ordered bilayer structures, and rather resulted in inhomogeneous phase distribution within the films. 


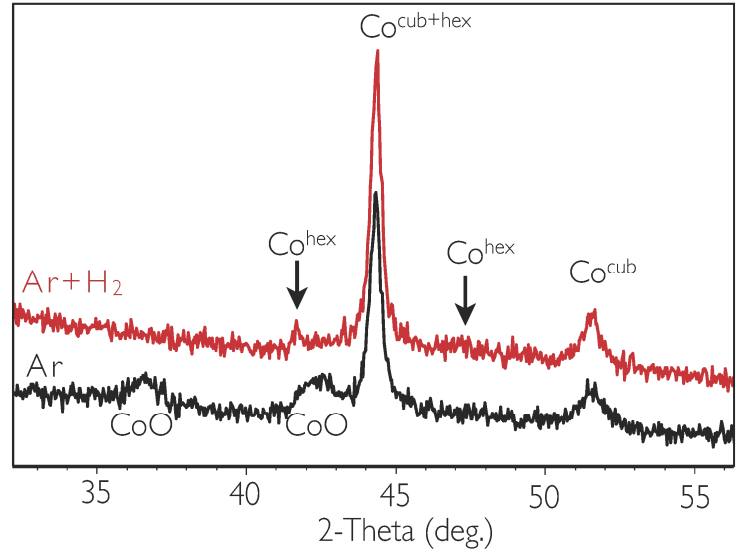

Figure 9. XRD of films heated in inert $(\mathrm{Ar})$ and reducing $\left(\mathrm{Ar} / \mathrm{H}_{2}\right)$ atmosphere, and unexposed to air before and during analysis.
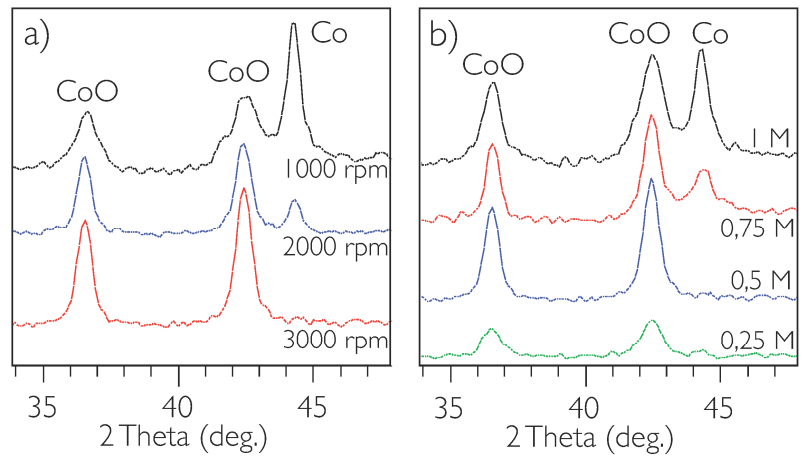

Figure 10. GIXRD of films heated at $5^{\circ} \mathrm{C} / \mathrm{min}$ in $\mathrm{N}_{2}$ followed by air oxidation in room temperature, a) films prepared by spin-coating a $0.50 \mathrm{M}$ solution at 1000, 2000, and $3000 \mathrm{rpm}$, respectively, and b) films prepared from solutions of different concentrations by spin-coating at $3000 \mathrm{rpm}$.

\section{Conclusions}

We have demonstrated a solution-chemical route to cobalt oxides and composites. Dense films were obtained by spin-coating silicon substrates followed by heating to $500^{\circ} \mathrm{C}$. Phase pure $\mathrm{Co}_{3} \mathrm{O}_{4}$ was obtained by heating in air or oxygen, while $\mathrm{CoO}$ was obtained by heating in inert atmosphere followed by change of atmospheres from $\mathrm{N}_{2}$ to air or $\mathrm{O}_{2}$ at $120^{\circ} \mathrm{C}$ during cooling. Composite films of $\mathrm{Co}-\mathrm{CoO}$ were obtained by heating in inert atmosphere followed by air oxidation, and films obtained from 1.0 or $0.75 \mathrm{M}$ solutions yielded bilayer $\mathrm{Co}-\mathrm{CoO}$ structures. $\mathrm{CoO}-\mathrm{Co}_{3} \mathrm{O}_{4}$ composite films were obtained by addition of $1 \% \mathrm{O}_{2}$ to the inert atmosphere from $450^{\circ} \mathrm{C}$ during heating or at the beginning of the cooling phase. Composite films with different phase ratios could be obtained, depending on the temperature for changing from inert to oxidizing atmosphere. Both the heat-treatment atmospheres and the film thickness, which decreases with increasing spin velocity and with decreasing concentration of the precursor solution, were found to be important parameters in controlling the phase ratios of the films. The results open for tailoring of chemical and physical properties through control of thickness and phase compositions in cobalt oxide and composite films. This is interesting for practical application such as catalysis, as well as for fundamental studies of e.g. magnetism in nanosystems.

\section{Acknowledgements}

This study was financed by the Swedish research council (VR), 2005-4829, and the Swedish foundation for strategic research (SSF), A307:225g.

\section{References}

[1] N.N Greenwood, and A. Earnshaw (1984) Chemistry of the Elements, Butterworth-Heinemann Ldt, Oxford, UK, ISBN 0-7506-2832-4, pp 1290-1327

[2] E. Wilczkowska, K. Krawczyk, J. Petryk, J. Sobczak, Z. Kaszkur, (2010) Appl. Catal. A-Gen. 389 (1-2); 165-172

[3] H. Hamada, M. Haneda, N. Kakuta, H. Miura, K. Inami, T. Nanba, W.Q. Hua, A. Ueno, H. Ohfune, Y. Udagawa, (1997) Chem. Lett.; 887-888

[4] P. Poizot, S. Laruelle, S. Grugeon, L. Dupont, J.M. Tarascon, (2000) Nature 407; 496-499

[5] C. Wang, D. Wang, Q. Wang, L. Wang, (2010) Electrochimica Acta, 55; 6420-6425

[6] Y. Wang, Z.W. Fu, Q.Z. Qin, (2003) Thin Solid Films 441(1-2); 19-24

[7] F. Huang, H. Zhan, Y.H. Zhou, (2003) Chinese J. Chem. 21(10); 1275-1279

[8] J. Wollenstein, M. Burgmair, G. Plescher, T. Sulima, J. Hildenbrand, H. Bottner, I. Eisele, (2003) Sensor. Actuat. B-Chem. 93(1-3); 442-448

[9] D. Barreca, E. Comini, A. Gasparotto, C. Maccato, A. Pozza, C. Sada, G. Sberveglieri, E. Tondello, (2010) J. Nanosci. Nanotechno. 10(12); 8054-8061

[10] H.S. Shim, V.R. Shinde, H.J. Kim, Y.E. Sung, W.B. Kim, (2008) Thin Solid Films 516(23); 8573-8578

[11] H. Yamamoto, T. Naito, M. Terao, T. Shintani, (2002) Thin Solid Films 411(2); 289-297

[12] F. Svegl, B. Orel, M.G. Hutchins, K. Kalcher, (1996) J. Electrochem. Soc. 134(5);1532-1539

[13] A. Berger, M.J. Pechan, R. Compton, J.S. Jiang, J.E. Pearson, S.D. Bader, (2001) Physica B 306; 235-239.

[14] M. Rubinstein, P. Lubitz, S.F. Cheng, (1999) J. Magn. Magn. Mater. 195; 299-306

[15] C.N.R. Rao, V.V. Agrawal, K. Biswas, U.K. Gautam, M. Ghosh, A. Govindaraj, G.U. Kulkarni, K.P. Kalyanikutty, K. Sardar, S.R.C. Vivekchand, (2006) Pure Appl. Chem. 78(9); $1619-1650$

[16] L. Armelao, D. Barreca, S. Gross, A. Martucci, M. Tieto, E. Tondello, (2001) J. Non-Cryst. Solids 293-295; 477-482

[17] K. Sinko, G. Szabo, M. Zrinyi, (2011) J. Nanosci. Nanotechno. 11(5); 4127-4135

[18] Q. Guo, X. Guo, Q. Tian, (2010) Adv. Powder Technol. 21; $529-533$ 
[19] D. Gallant, M. Pézolet, S.J. Simard (2006) Phys. Chem. B. 110; $6871-6880$

[20] Y.W.D. Chen. R.N. Noufi, (1984) J. Electrochem. Soc. 131; 731-735

[21] K.M. Nam, J.H. Shim, D.W. Han, H.S. Kwon, Y.M. Kang, Y. Li, H. Song, W.S. Seo, J.T. Park, (2010) Chem. Mater. 22; $4446-4454$

[22] J. Ahmed, T. Ahmad, K.V. Ramanujachary, S.E. Lofland, A.K. Ganguli, (2008) J. Colloid Interf. Sci. 321(2); 434-441

[23] G. Sun, X. Zhang, M. Cao, B. Wei, C. Hu, (2009) J. Phys. Chem. C 113; 6948-6954

[24] H.J. Nam, T. Sasaki, N. Koshizaki (2006) J. Phys. Chem. B $110 ; 23081-23084$

[25] Y. Ren, P.G. Bruce, Z. Ma, (2011) J. Mater. Chem. 21; 9312-9318

[26] H.K. Lin, H.C. Chiu, H.C. Tsai, S.H. Chien, C.B. Wang, (2003) Catal. Lett. 88(3-4); 169-174

[27] G. Westin, A. Pohl, M. Ottosson, K. Jansson, (2007) Thin Solid Films 515; 7751-7757
[28] R. Knut, J.M. Wikberg, K. Lashgari, V.A. Coleman, G. Westin, P. Svedlindh, O. Karis, (2010) Phys. Rev. B 82; 094438

[29] G. Westin, K. Jansson, A. Pohl, M. Leideborg, (2004) J. Sol-Gel Sci. Techn. 31; 25-29

[30] G. Westin, M. Leideborg, K. Lashgari, V.A. Coleman, K. Jansson, A. Pohl, (2009) Int. J. Nanotechnol. 6; 828-849

[31] A. Pohl, G. Westin, (2005) J. Am. Ceram. Soc. 88(8); 2099-2105

[32] G. Westin, M. Ottosson, A. Pohl, (2008) Thin Solid Films 516; $4673-4678$

[33] Å. Ekstrand, K. Jansson, G. Westin, (2005) Chem. Mater. 17; 199-205

[34] Å. Ekstrand, K. Jansson, G. Westin, (2000) Sol-Gel Sci. Techn. $19 ; 353-356$

[35] U. Lagerqvist, P. Svedlindh, K. Gunnarsson, J. Lu, L. Hultman, M. Ottosson, A. Pohl, unpublished. 